Primljen / Received: 7.1.2016. Ispravljen / Corrected: 13.8.2016. Prihvaćen / Accepted: 30.9.2016. Dostupno online / Available online: 10.1.2018.

\section{Different approaches to two-dimensional numerical modelling of natural watercourses}

Authors:

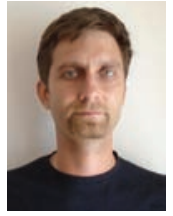

${ }^{1}$ Assist. Prof. Zoltan Horvat, PhD. CE horvath.czoczek.zoltan@gmail.com

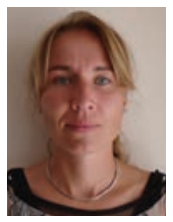

${ }^{1}$ Assist.Prof. Mirjana Horvat, PhD. CE isic.marijana@gmail.com

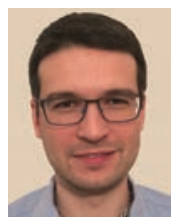

${ }^{2}$ Assist.Prof. Nikola Rosić, PhD. CE nrosic@grf.bg.ac.rs

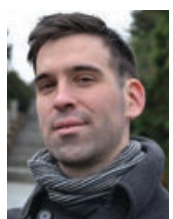

${ }^{2}$ Budo Zindović, MSc. CE bzindovic@hikom.grf.bg.ac.rs

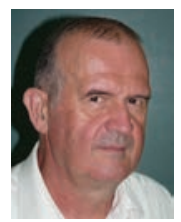

2Prof. Radomir Kapor, PhD. CE rkapor@hikom.grf.bg.ac.rs

${ }^{1}$ University of Novi Sad

Faculty of Civil Engineering Subotica

2University of Belgrad

Faculty of Civil Engineering

\section{Zoltan Horvat, Mirjana Horvat, Nikola Rosić, Budo Zindović, Radomir Kapor}

Subject review

\section{Different approaches to two-dimensional numerical modelling of natural watercourses}

Results obtained by analysis of three different approaches to numerical modelling of open watercourses are presented in the paper. Two examples of flow, uniform flow on the physical model of a curve at the Tisza River and nonuniform flow at the Danube River, are analysed. Standard error analysis has revealed that results of the similar order of magnitude are obtained in implementation of two numerical methods in which computational grids are used, while the method in which computational grid is not used, i.e. the smoothed particle hydrodynamics method, requires further improvements to enable successful modelling of the gradually variable flow.

Key words:

2D flow, finite element method, finite difference method, smoothed particle hydrodynamics method

Pregledni rad

Zoltan Horvat, Mirjana Horvat, Nikola Rosić, Budo Zindović, Radomir Kapor

\section{Različiti pristupi dvodimenzionalnom numeričkom modeliranju prirodnih vodotoka}

U radu su prikazani rezultati analize tri različita pristupa numeričkom modeliranju otvorenih vodotoka. Analizirana su dva primjera strujanja, jednoliko strujanje na fizikalnom modelu krivine na rijeci Tisi i nejednoliko strujanje na rijeci Dunavu. Analiza standardne pogreške pokazala je da se upotrebom dviju numeričkih metoda u kojima se koriste računske mreže dobivaju rezultati istog reda točnosti, dok metoda u kojoj se ne koristi računska mreža, metoda hidrodinamike izglađenih čestica, zahtijeva daljnja poboljšanja kako bi se uspješno modeliralo postupno promjenjivo strujanje.

Ključne riječi:

$2 \mathrm{D}$ strujanje, metoda konačnih elemenata, metoda konačnih razlika, metoda hidrodinamike izgladenih čestica

Übersichtsarbeit

Zoltan Horvat, Mirjana Horvat, Nikola Rosić, Budo Zindović, Radomir Kapor

Unterschiedliche Ansätze in der zweidimensionalen numerischen Modellierung von natürlichen Gerinnen

In der Arbeit werden die Ergebnisse von drei unterschiedlichen Ansätzen bei der numerischen Modellierung von offenen Gerinnen dargestellt. Es wurden zwei Strömungsbeispiele analysiert, die gleichförmige Strömung am physikalischen Modell einer Windung am Fluss Tisa und die ungleichförmige Strömung an der Donau. Die Auswertung eines Standardfehlers hat zeigt, dass bei Anwendung der zwei numerischen Methoden, bei welchen Rechnernetze zur Anwendung kommen, vergleichbar präzise Ergebnisse gewonnen werden, während die Methode, in welcher das Rechnernetz nicht angewendet wird, bzw. die Methode der geglätteten Teilchen-Hydrodynamik, weitere Verbesserungen bedarf.

Schlüsselwörter:

2D Strömung, Methode der finiten Elemente, FEM, Methode der geglätteten Teilchen-Hydrodynamik 


\section{Introduction}

The development and testing of reliable and accurate mathematical flow models is of great interest since nearly all processes in natural watercourses are considerably influenced by complex flow conditions. Hydraulic and environmental engineering covers the fields of sediment transport, river morphology, constituent transport, and the related influence on various life forms and their habitat. Therefore, a proper flow-field computation should be the first step in any analysis concerning natural watercourses. Accordingly, the objective of this paper is to conduct a study that investigates three different approaches to the free surface flow modelling. The first implemented approach is the MoBed2 code [1], which is a well-established grid-based method that utilizes the operator splitting technique (fractional step method) on a structured computational grid. The second computer code is the Telemac-2D, which also makes use of the fractional step method, but relies on the finite element approach, based on an unstructured computational mesh [2]. Even though different authors [3] have developed accurate methods for wetting and drying, grid-based solvers are restricted in cases of rapidly changing flows. On the contrary, methods relying on particle tracking are very adjustable in this respect [4]. If Smoothed Particle Hydrodynamics (SPH) based methods prove to offer satisfactory results in slowly varying flow as the standard grid-based methods, then it can reasonably be stated that future natural watercourses flow modelling techniques should build upon this method.

The importance of numerical modelling of open channel flow in hydraulic engineering is reflected upon by a great number of developed numerical models and approaches [1, 5-8]. Various authors, aiming for the same goal (a more accurate and practical mechanism for predicting floods, flow domains, hydraulic effect on structures, etc.) used different numerical approaches, the finite element method [2], finite volume method [9], finite difference method [10], SPH methods [11], etc. When investigating numerical models, a typical technique is to use laboratory or field measurements, with well-defined domains and boundary conditions, as a verification tool for the developed model. As a result, most published papers assess accuracy of the model solely by comparing the computed and measured velocity values, free surface elevations, etc. Another approach in identifying the models accuracy is to compare the results obtained by the developed model with the results acquired by an existing and well established numerical model. However, rarely do researchers try to estimate the general applicability of a certain numerical approach by comparing it to both: other numerical approaches as well as measured data. The authors of this paper used three different numerical models in order to establish whether any among the considered methods produces generally better results. In doing so, the three examined numerical models were used to simulate steady flow, and two of them (MoBed2 and Telemac-2D) were employed to simulate the unsteady open channel flow. The computed results were evaluated by comparison with measured velocities, and by evaluation using appropriate error norms.

\section{Governing equations}

The mathematical model for river flow is based on depthaveraged Navier-Stokes equations, also known as shallow-water equations. The governing equations are mass and momentum conservation equations in Cartesian coordinates [8]:

$\frac{\partial h}{\partial t}+\frac{\partial h u}{\partial x}+\frac{\partial h v}{\partial y}=0$

$\frac{\partial}{\partial t}(h u)+\frac{\partial}{\partial x}\left(h u^{2}\right)+\frac{\partial}{\partial y}(h u v)=-g h \frac{\partial}{\partial x}\left(z_{b}+h\right)-\frac{1}{\rho}\left(\tau_{b x}+\frac{\partial}{\partial x}\left(h \tau_{x x}\right)+\frac{\partial}{\partial y}\left(h \tau_{y x}\right)\right)$

$\frac{\partial}{\partial t}(h v)+\frac{\partial}{\partial x}(h u v)+\frac{\partial}{\partial y}\left(h v^{2}\right)=-g h \frac{\partial}{\partial y}\left(z_{b}+h\right)-\frac{1}{\rho}\left(\tau_{b y}+\frac{\partial}{\partial x}\left(h \tau_{x y}\right)+\frac{\partial}{\partial y}\left(h \tau_{y y}\right)\right)$

where $h$ denotes water depth, $u$ and $\mathrm{n}$ are velocity components in $x$ and $y$ coordinate directions, $t$ marks time, $g$ represents gravitational acceleration, $z_{b}$ denotes bed elevation, $\tau_{x x^{\prime}} \tau_{x y^{\prime}} \tau_{y x^{\prime}}$ and $\tau_{y y}$ represents joined action of turbulent stresses and dispersion terms, $\tau_{b x^{\prime}}$ and $\tau_{b y}$ are bottom shear stresses in $x$ and y coordinate directions. The bottom shear stresses were estimated by the generalized Manning formula for two-dimensional flow:

$\tau_{b x}=-\frac{\rho g n^{2}}{h^{1 / 3}} u \sqrt{u^{2}+v^{2}}, \tau_{b y}=-\frac{\rho g n^{2}}{h^{1 / 3}} v \sqrt{u^{2}+v^{2}}$

where $h$ denotes water depth, $u$ and $\mathrm{n}$ are velocity components in $x$ and $y$ coordinate directions, $t$ marks time, $g$ represents gravitational acceleration, $z_{b}$ denotes bed elevation, $\tau_{x x^{\prime}} \tau_{x y^{\prime}} \tau_{y x^{\prime}}$ and $\tau_{y y}$ represents joined action of turbulent stresses and dispersion terms, $\tau_{b x^{\prime}}$ and $\tau_{b y}$ are bottom shear stresses in $x$ and $y$ coordinate directions. The bottom shear stresses were estimated by the generalized Manning formula for two-dimensional flow: [11-13].

\subsection{Telemac-2D code}

The Telemac system was developed by the Laboratoire National d'Hydraulique (LNH) at Electricité de France. This system is made of a series of computer programs based on finite element techniques for the simulation of different hydraulic situations. The Telemac-2D program is described in detail in this subsection. Telemac-2D implements the finite element approach to attain the solution of the shallow water equations resulting in the known values of depth and two velocity components at each point inside the computational domain [14]. The computational points are defined through the discretization process while creating the computational mesh. To achieve flexibility in the domain discretization, Telemac-2D implements an unstructured grid by incorporating triangular elements. As for the solution algorithms, Telemac-2D offers different approaches, e.g. the fractional step technique using the method of characteristics (MOC), several variants of the Streamline Upwind PetrovGalerkin (SUPG) method, and a hybrid scheme that combines the MOC and SUPG approaches [8]. Since the MoBed2 code implements the MOC with the operator splitting approach 
of Yanenko [15], the authors found it justifiable to select this approach in the Telemac-2D model (fractional step technique using the characteristics method optimized for finite-element framework). The solution procedure of eqs. (1)-(3) consists of two parts. The first part is the advection step:

$\left(\frac{\partial h}{\partial t}\right)^{a}+u \frac{\partial h}{\partial x}+v \frac{\partial h}{\partial y}=0$

$\left(\frac{\partial u}{\partial t}\right)^{a}+u \frac{\partial u}{\partial x}+v \frac{\partial u}{\partial y}=0$

$\left(\frac{\partial v}{\partial t}\right)^{a}+u \frac{\partial v}{\partial x}+v \frac{\partial v}{\partial y}=0$

which is followed by the second, combined propagation and diffusion step:

$\left(\frac{\partial h}{\partial t}\right)^{a+d+p}-\left(\frac{\partial h}{\partial t}\right)^{a}+h \frac{\partial u}{\partial x}+h \frac{\partial v}{\partial y}=0$

$\left(\frac{\partial u}{\partial t}\right)^{a+d+p}-\left(\frac{\partial u}{\partial t}\right)^{a}=-g \frac{\partial}{\partial x}\left(z_{b}+h\right)-\frac{1}{\rho h}\left(\tau_{b x}+\frac{\partial}{\partial x}\left(h \tau_{x x}\right)+\frac{\partial}{\partial y}\left(h \tau_{y x}\right)\right)$ (6)

$\left(\frac{\partial v}{\partial t}\right)^{a+d+p}-\left(\frac{\partial v}{\partial t}\right)^{a}=-g \frac{\partial}{\partial y}\left(z_{b}+h\right)-\frac{1}{\rho h}\left(\tau_{b y}+\frac{\partial}{\partial x}\left(h \tau_{x y}\right)+\frac{\partial}{\partial y}\left(h \tau_{y y}\right)\right)$

Eqs. (6) and include the remaining parts of the mass and momentum conservation eqs. (2). Upper indexes $a$ and $a+d+p$ respectively mark the two subsequent computational steps (the advection step and the combined advection, diffusion, and propagation steps). The integration of equations (5) and (6) is performed along the characteristics by dividing them into an arbitrary number of integration segments.

\subsection{MoBed2 code}

The MoBed2 computer code is presented in much detail, at its present stage of development, by the authors in their previous paper [1]. This model incorporates three dimensional Reynoldsaveraged Navier-Stokes equations that were transformed in the orthogonal curvilinear coordinate system. The equations were depth-averaged and solved using the fractional step method [15], which resulted in three subsequent computational steps. In order to obtain a certain level of clarity, the aforementioned equations are presented in the Cartesian coordinate system. Equations implemented in MoBed2, originally proposed by Yanenko [15], are optimal for body-fitted finite-difference numerical models. These equations are slightly different from the ones solved in Telemac-2D (5)-(6), which in turn are optimized within the finite-element framework. The advection step in MoBed 2 includes momentum equations only (in contrast, eqs. (6) include a part of the continuity equation as well), while the diffusion and propagation steps are solved separately. The advection step equations are solved using the MOC. Similar to Telemac-2D, the integration along characteristic curves is accomplished by dividing them into an arbitrary number of straight sub-segments [1]. The resulting equations for velocity components are nonlinear, and are solved using the NewtonRaphson iterative algorithm [16-18]. The diffusion step equations:

$$
\begin{aligned}
& \left(\frac{\partial u}{\partial t}\right)^{a+d}-\left(\frac{\partial u}{\partial t}\right)^{a}=\frac{1}{h \rho}\left(\frac{\partial}{\partial x}\left(\tau_{x x} h\right)+\frac{\partial}{\partial y}\left(\tau_{y x} h\right)\right) \\
& \left(\frac{\partial v}{\partial t}\right)^{a+d}-\left(\frac{\partial v}{\partial t}\right)^{a}=\frac{1}{h \rho}\left(\frac{\partial}{\partial x}\left(\tau_{x y} h\right)+\frac{\partial}{\partial y}\left(\tau_{y y} h\right)\right)
\end{aligned}
$$

are discretized using finite differences with the Crank-Nicolson time-integration scheme [19]. Equations (7) are linearized with the alternating direction implicit (ADI) method [20] resulting in a three-diagonal system of equations. This system is efficiently solved using the Thomas (double-sweep) algorithm [1], which in turn notably reduces the computation time.

The propagation step includes the remaining terms from the momentum equations and the continuity equation:

$$
\begin{aligned}
& \left(\frac{\partial u}{\partial t}\right)^{a+d+p}-\left(\frac{\partial u}{\partial t}\right)^{a+d}=-g h \frac{\partial}{\partial x}\left(z_{b}+h\right)-\frac{\tau_{b x}}{\rho h} \\
& \left(\frac{\partial v}{\partial t}\right)^{a+d+p}-\left(\frac{\partial v}{\partial t}\right)^{a+d}=-g h \frac{\partial}{\partial y}\left(z_{b}+h\right)-\frac{\tau_{b y}}{\rho h} \\
& \frac{\partial h}{\partial t}+\frac{\partial}{\partial x}(h u)+\frac{\partial}{\partial y}(h v)=0
\end{aligned}
$$

Equations (8) are transformed by introducing the time weighting coefficient. The first two equations are linearized and rearranged in order to eliminate the now appearing non-linear terms hu and $h v$ in the continuity equation. As a result, these three equations are combined into a single equation with only one unknown, the depth increment [1]. To avoid numerical instability, the resulting equation is discretized on a staggered grid, linearized using the ADI method, and solved with the double-sweep algorithm.

\subsection{Modified SWE-SPHysics code}

The smoothed particle hydrodynamics (SPH) was originally developed for simulation of processes in astrophysics [21, 22]. The SPH is a particle method that does not need a grid to calculate spatial derivatives. Instead, the derivatives are found by analytical differentiation of the interpolation formulae. The equations of momentum and energy are transformed into sets of ordinary differential equations. The SPH is an interpolation method which allows any function to be expressed in terms of its values at a set of disordered points - the particles. The adopted interpolation has a local character, since physical quantities in any particle are determined using the same quantities of neighbouring particles and a weighting function. The value of this function decreases as the distance between neighbouring particles increases. The computational procedures implemented in the SWE-SPHysics computer code are given, along with detailed explanations, by [11-13]. Solving the depth integrated equations of mass and momentum using the SPH requires their representation in the Lagrangian form: 
$\frac{\mathrm{d} h_{p}}{\mathrm{~d} t}=-h_{p} \nabla \cdot \mathbf{u}$

$\frac{\mathrm{d} \mathbf{u}}{\mathrm{d} t}=-\mathrm{g} \nabla h_{p}+\mathrm{g}\left(\nabla \mathbf{z}_{b}+\mathbf{S}_{f}+\boldsymbol{\Theta}_{t u r b}\right)$

where $h_{p}$ is water depth and $\nabla z_{b}$ is bottom elevation. The source term $S_{f}$ represents the bed friction computed using the Manning's friction coefficient $n$. The last term on the right-hand side of eqn (10) $\Theta_{\text {turb }}$ accounts for the turbulence effect. This term was used in the presented analysis as replacement for the artificial viscosity term that is used in the original SWE-SPHysics code. The right hand side terms in eqns. (9) and (10) are computed using the interpolation based on the following simple concept:

$A(\mathbf{r}) \approx \int_{\Omega} A\left(\mathbf{r}^{\prime}\right) W\left(\mathbf{r}-\mathbf{r}^{\prime}, I\right) \mathrm{d} \mathbf{r}^{\prime} \approx \sum_{j} m_{j} \frac{A_{j}}{\rho_{j}} W\left(\mathbf{r}-\mathbf{r}^{\prime}, I\right)$

Equation (11) can be used to yield SPH approximations for differential operator, given by::

$\nabla \cdot A(\mathbf{r}) \approx-\int_{\Omega} A\left(\mathbf{r}^{\prime}\right) \nabla \cdot W\left(\mathbf{r}-\mathbf{r}^{\prime}, I\right) \mathrm{d} \mathbf{r}^{\prime} \approx-\sum_{j} m_{j} \frac{A_{j}}{\rho_{j}} \nabla \cdot W\left(\mathbf{r}-\mathbf{r}^{\prime}, I\right)$

In eqs. (11) and (12) $A$ denotes an arbitrary function, $\mathbf{r}$ is the particle's position vector at which function $A$ is evaluated, index $j$ marks the neighbour particle at position defined by $\mathbf{r}^{\prime}$, and $\Omega$ denotes the computational domain. The weighting function (kernel) is represented by $W$, while / is the smoothing length used as a measure for defining the distance of the furthest particle that influences the value of any function in the observed particle. In the SWE-SPHysics code, it is impossible to define an arbitrary velocity distribution at the boundaries. The authors are still working on this issue that affects the presented comparison to a certain extent. However, in this paper, the approximately symmetric (non-uniform) velocity distribution at the upstream boundary was obtained using the original procedure based on the variation of the Manning's roughness coefficient along the boundary cross section.

In order to simulate steady flow, constant boundary conditions must be applied. The time integration of the velocities and positions of the particles is conducted using the leap-frog scheme $[11,12]$. In cases of dynamic simulations, particles are moving which results in variable particle density over time. Therefore, the conservation of the required accuracy and computer efficiency calls for variation of the smoothing length as well [23]. The computation of the water depth and the smoothing length is performed for each particle using the Newton-Raphson iterative procedure.

The interpolation concept given by eq. (11) was used In order to extract the results in discrete points where measurements were conducted.

\subsection{Turbulence model}

As the turbulence cannot be taken into account by the SWESPHysics code, we implemented the zero equation turbulence model following Boussinesq approximation for the diffusion term. The same turbulence model was used in MoBed 2 and Telemac:

$\frac{1}{\rho} \bar{\tau}=v_{t}\left[\begin{array}{cc}\tau_{x x} & \tau_{x y} \\ \tau_{y x} & \tau_{y y}\end{array}\right]=v_{t}\left[\begin{array}{cc}2 \frac{\partial u}{\partial x} & \left(\frac{\partial u}{\partial y}+\frac{\partial v}{\partial x}\right) \\ \left(\frac{\partial u}{\partial y}+\frac{\partial v}{\partial x}\right) & 2 \frac{\partial v}{\partial y}\end{array}\right]$

where $\bar{\tau}$ represents the turbulent stress tensor. Eddy viscosity $v_{t}$ was calculated using the following formula [24]:

$v_{t}=\alpha_{t} h u_{*}$

where $u_{*}$ is the bend shear velocity, $u_{*}=\left[C_{f}\left(u^{2}+v^{2}\right)\right]^{1 / 2}$. The coefficient $\alpha=\kappa / 6$ was used with $\kappa$ being the Von Karman constant $(\kappa=0.4)$.

\section{Measurements}

The considered numerical models were tested for two independent test cases. The first test case involved laboratory measurements of steady flow in a curved channel. This data set was used to evaluate the ability of three compared models to conduct steady flow analysis in a complex flow domain. The basic information on these measurements is given in Section 3.1. For the second test case, field measurements were used in order to analyse the considered models' capability to simulate unsteady flow in natural watercourses, as presented in Section 3.2.

\subsection{Laboratory measurements}

The steady flow measurements were conducted at the laboratory of the Jaroslav Cerni Institute for the Development of Water Resources in Belgrade, Serbia, using a physical model of a riverbed. The total length of the physical model was $22 \mathrm{~m}$, with the average width of approximately $1 \mathrm{~m}$. Since the bed was designed from the same material throughout the domain, it was reasonable to assume that hydraulic roughness is uniform. Bed elevations of the laboratory model are presented in Figure 1. In addition, Figure 1 contains the constructed mesh, defined with 52 data ranges (cross-sections) with 9 verticals in each, giving the total of 468 computational points. While the bed elevation measurements were performed at each point, forty data ranges were selected for the flow field measurements. Velocity measurements were carried out using a current meter. Since the measurements were executed for the purpose of modelling a two-dimensional depth averaged flow, it was necessary to provide a representative depth averaged velocity for every vertical. This was enabled by conducting multiple velocity measurements at different depths at each vertical (no more than four measurements per vertical), consequently making it possible to acquire the depth averaged velocity. The upstream boundary condition of the physical model was set to constant values of unit discharge, while measuring the free surface elevation for the downstream boundary condition. More details about the measurements can be found in the Ph.D. thesis [25]. 


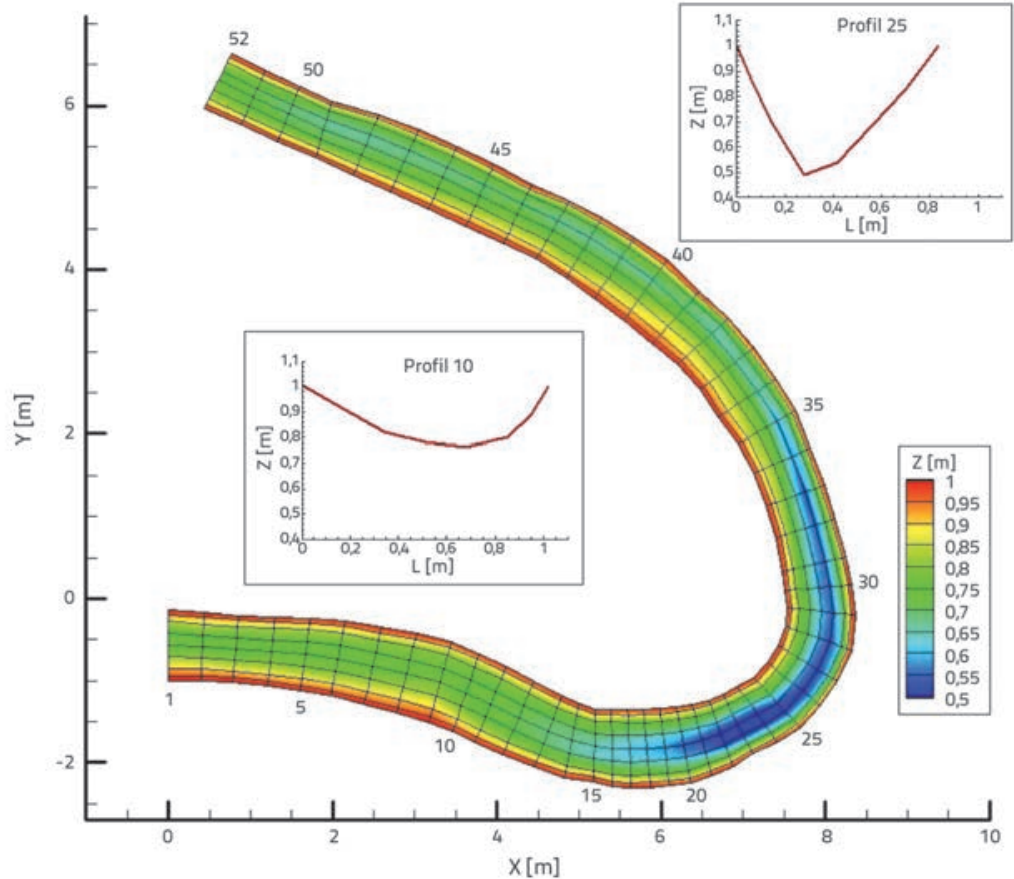

Figure 1. Laboratory model domain

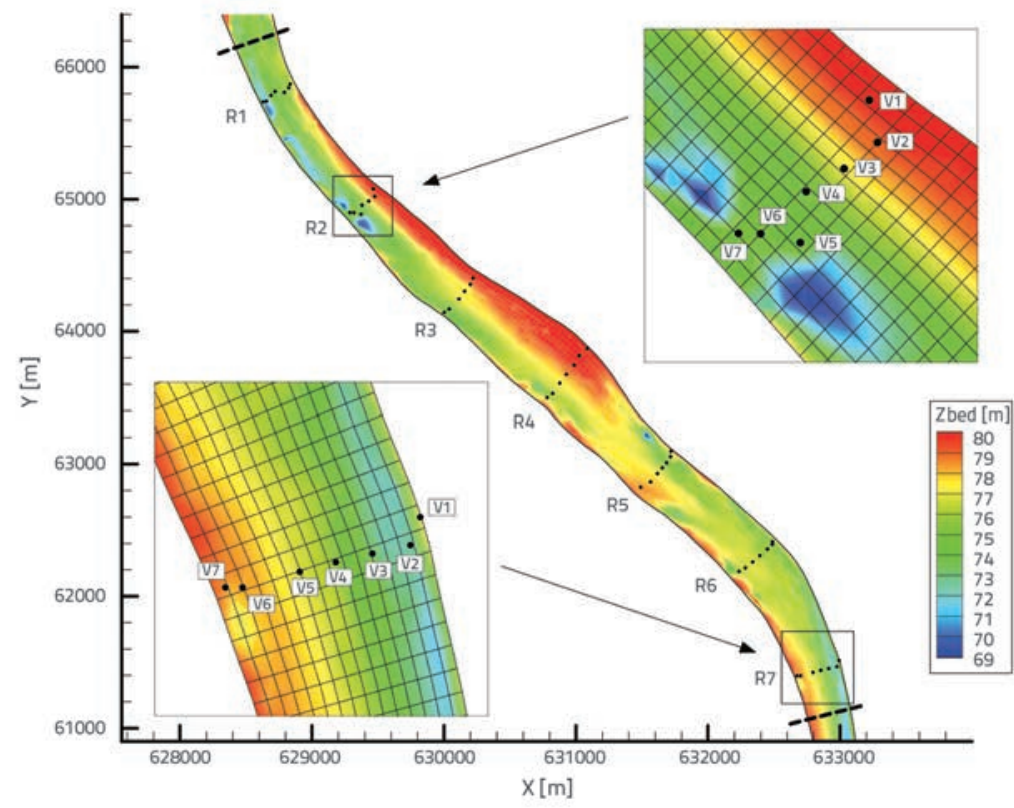

Figure 2. Field measurements - Reach of the Danube River from Mohacs to Bezdan

inside the considered reach for velocity measurements (Figure 2). These ranges were placed between rkm 1438 and rkm 1432, at roughly $1 \mathrm{~km}$ apart, outlining a reach with detailed measurements of approximately $7 \mathrm{~km}$ in length. Each range had seven verticals, where velocity distribution profiles were collected using an acoustic Doppler current profiler (ADCP).

The velocity distribution measurements were carried out in accordance with the research presented in [26, 27]. The fixed-vessel ADCP velocity record time was 10 min, ensuring the averaging of instantaneous velocity profiles in verticals. The selected recording time was monitored during the data collection campaign by real-time averaging of velocity profiles, and verified as adequate for every vertical separately. The post processing of the ADCP data provided velocity distributions for each vertical. The necessary boundary conditions for flow computation were gathered during the data collection campaign by measuring discharges at Mohacs and water surface elevation in Bezdan twice a day. More details on these measurements are given in a previously published paper [1].

After obtaining velocity distributions for each vertical, the depth-averaging procedure must be conducted in order to acquire velocity values that are comparable with the developed twodimensional numerical model.

\section{Analysis of results}

The evaluation of the studied numerical models was performed for two case studies. For the first test case, a steady flow analysis in a river bed was conducted using the laboratory measurements described in Section 3.1, while the second case study explores unsteady flow in natural watercourses, as presented in Section 3.2. It should be outlined that both examples refer to natural watercourses with complex bed morphology, complementing the

\subsection{Field measurements}

Field measurements were conducted on the reach of the Danube River located in the border area between Hungary and Serbia. The data collection campaign was completed in five days (May 2011). Within the selected sight, bounded by Bezdan (rkm 1425.5) in Serbia and Mohacs (rkm 1446.9) in Hungary (Figure 2), the bathymetry (bed elevation) data were collected at approximately $100 \mathrm{~m}$ intervals, resulting in 215 cross-sections overall. Seven data ranges were selected expectations of mathematical model application in hydraulic and environmental engineering.

The models were evaluated by comparing the measured and computed velocity components. To ensure a more profound understanding of the results, the presented analysis was extended with computed error norms $L_{1}, L_{2}$ and $L_{\infty}$ determined by eqns. (15). Values $x_{i}$ denote the difference between the measured and computed velocity components. The error norms were calculated for two velocity components separately, and are presented for both case studies: 
$L_{1}=\sum_{i=1}^{n}\left|x_{i}\right| \quad L_{2}=\sqrt{\sum_{i=1}^{n}\left|x_{i}\right|^{2}} \quad L_{\infty}=\underbrace{\max }_{1 \leq i \leq n}\left|x_{i}\right|$

\subsection{Steady flow analysis}

Numerical models considered in Section 2 were engaged in a steady flow simulation using the laboratory measurements described in Section 3.1. The upstream boundary condition was a constant discharge, while a steady water level elevation was maintained on the downstream end of the reach. In the case of MoBed2, the studied domain was described using the mesh presented in Figure 1. As mentioned before, this computational grid was defined through selected measurement points during the laboratory experiment. Telemac-2D was operated using a mesh with the same density and computational points distribution, the only difference being that selected cells were triangles in order to better accommodate the modelled domain. The third considered model was the modified SWESPHysics code, where a number of particles that best describe the investigated problem were assigned instead of designing a mesh. Setting the number of particles to match the number of computational points would severely decrease the quality of results. After careful consideration, it was established that the best option is to select 9000 as an initial number of particles, because an increase in the number of particles, while demanding more computational time, does not improve accuracy of results (as shown in Table 1). Nevertheless, this number of particles imposed the need for a very small time step (a fraction of a second), far smaller than the step used for the two other models.

Table 1. Steady flow analysis - Influence of the number of particles used in SPH simulations on the average error norm $L_{1}$ for the u velocity component and Computational time

\begin{tabular}{|c|c|c|}
\hline Number of particles & $\mathbf{L}_{\mathbf{1}}$ & Computational time [min] \\
\hline 9000 & 0.383 & 311 \\
\hline 15000 & 0.382 & 413 \\
\hline 30000 & 0.382 & 882 \\
\hline
\end{tabular}

The models were calibrated by changing the Manning's roughness coefficient to obtain satisfying correspondence between the measured and computed free-surface elevations. The Manning's roughness coefficient value of 0.020 was used in all three models. Following the calibration process, the models were evaluated by comparing the computed and measured velocity components. Figure 3 and Figure 4 successively present the $u$ and $v$ velocity components distribution in six selected data ranges $(10,19,20,25,30$ and 40). The measured values are described as "u(v)-meas", while the computed velocities are sequentially marked as "u(v)-Telemac2D" for the results acquired by the Telemac-2D model, "u(v)-MoBed2" for the results computed by the MoBed2 code, and "u(v)-SWE-SPH" for the results attained using the Modified SWE-SPHysics model. For a more thorough examination, additional error analysis was conducted. Using eqns. (15) error norms $L_{1}, L_{2}$ and $L_{\infty}$ were computed. Since every vertical has one $u$ and one $v$ velocity component, the error norms were
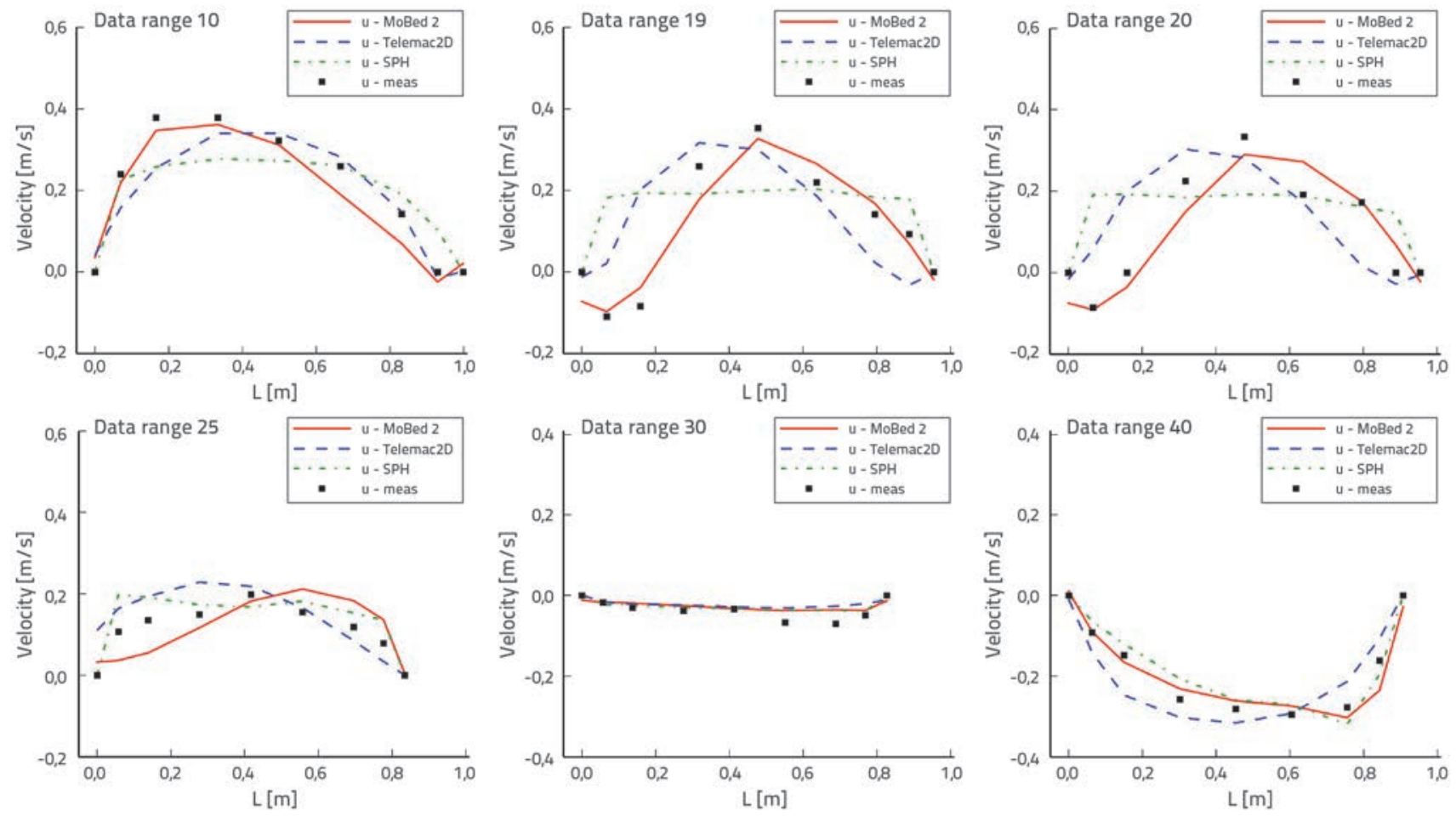

Figure 3. Steady flow analysis - velocity component $u$ 

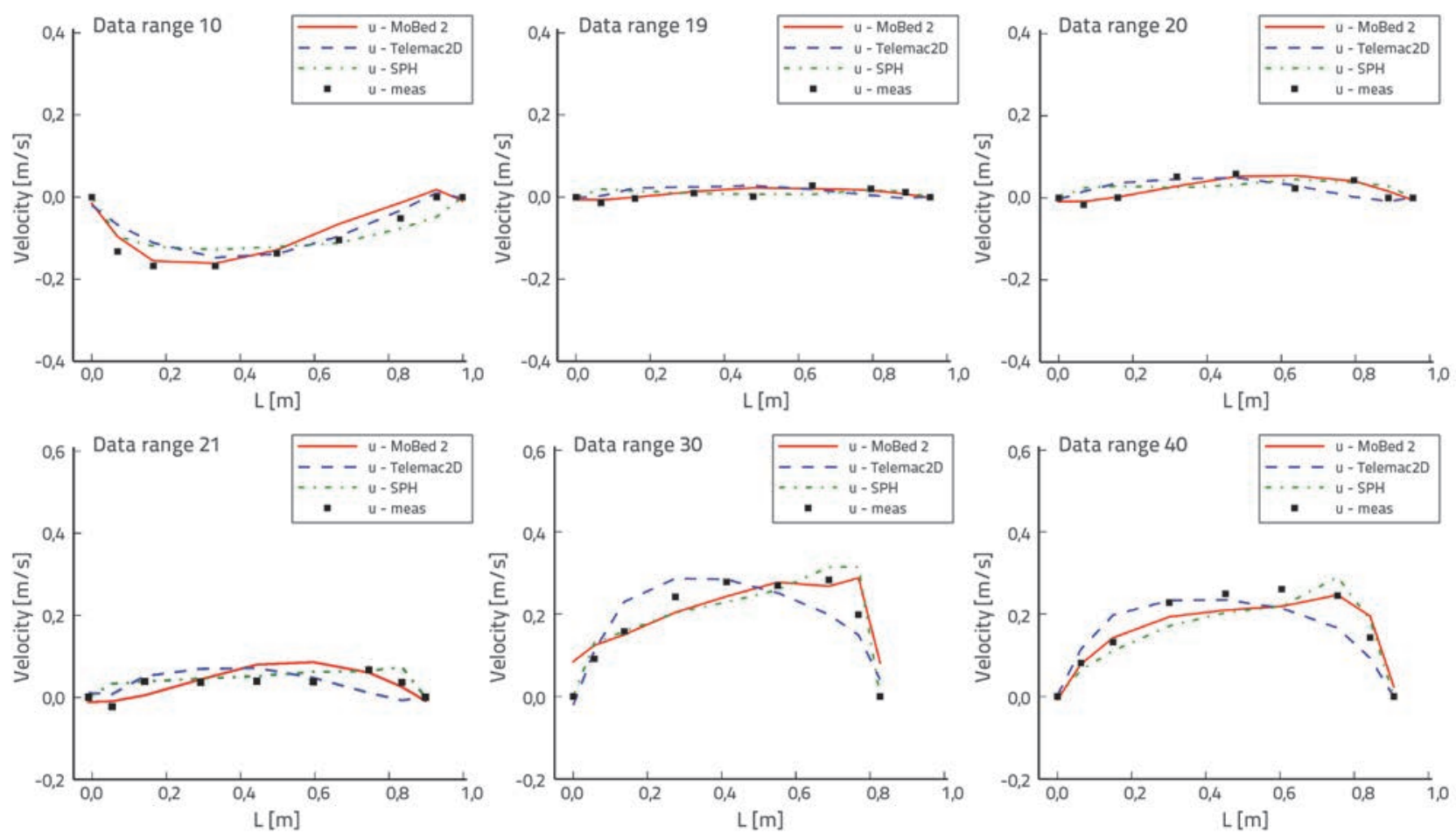

Figure 4. Steady flow analysis - velocity component $v$

determined to represent the discrepancy from the measured velocity component for the complete data range. Values are given for every data range with measurements (Figure 5). By evaluating the results visually, it can be concluded that there are distinctive variations among the measured and computed values. In order to extract a more unambiguous conclusion, the model performance was analysed by dividing the reach in three segments that displayed essentially different tendencies. The first segment
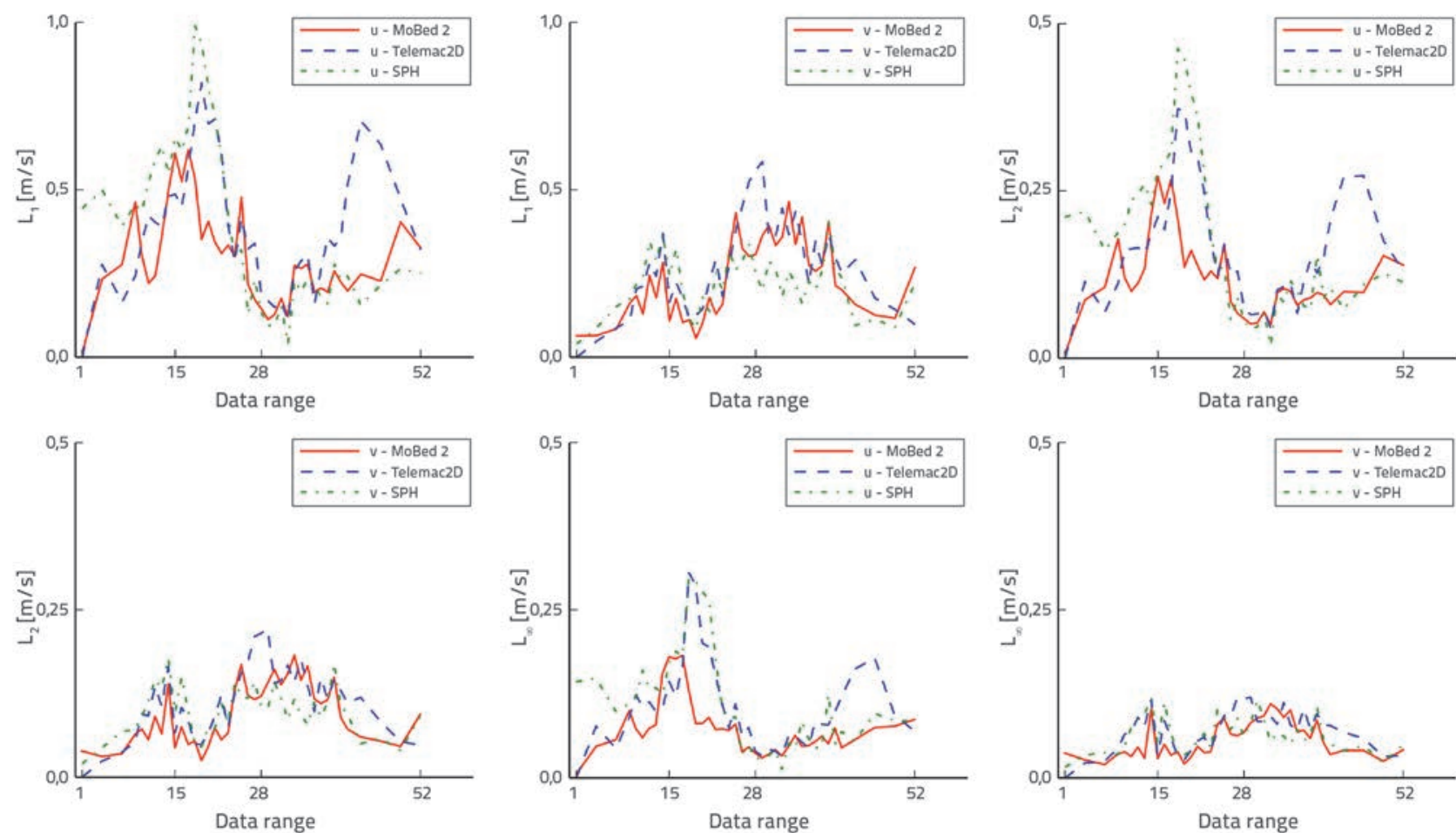

Figure 5. Steady flow analysis - Error norms for velocity components $u$ and $v$ 

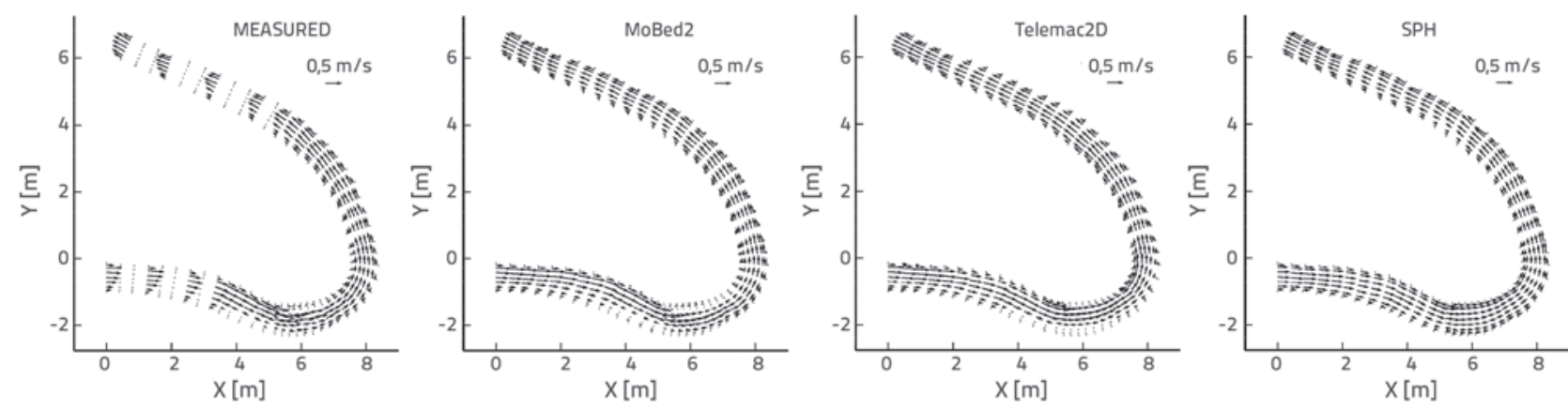

Figure 6. Steady flow analysis - two dimensional velocity plot

was at the upstream end of the domain (data ranges 1 to 15), the second enclosed the river bend itself (data ranges 16 to 28), while the third segment was at the downstream of the river bend (data ranges 29 to 52). The forthcoming conclusions are derived by simultaneously examining the results presented in figures 3 , 4 and 5.

In the first segment of the modelled domain, MoBed2 proved to have a slight advantage over the other two models. However, both MoBed2 and Telemac-2D managed to reproduce the tendencies observed in the laboratory experiment, i.e. greater velocity values on the left bank as depicted in data range 10, Figure 3 and Figure 4. Results acquired by modified SWESPHysics in this reach segment somewhat lag behind the other two models. This can be explained by inconsistency in definition of the upstream boundary condition. The numerical results for data ranges in the river bend have by far the greatest inconsistency compared to the measured values, as well as among themselves. Namely, MoBed2 was able to replicate the negative $u$ velocity components on the left bank, as presented in data ranges 19, 20 and 21, in Figure 3. On the other hand, Telemac-2D showed only a decrease of these velocities, nonetheless reflecting the registered trend. Finally, SWESPHysics had difficulties reproducing the previously illustrated tendency. The evaluation of the third segment of the physical model shows an alteration in the tested models accuracy. Conversely, SWE-SPhysics produced results closest to the measured values, as confirmed by the computed error norms given in Figure 5.
The velocity distribution over the modelled domain is presented in Figure 6. It should be noted that the measurements confirmed the presence of a region with small velocities, located near the right bank (between data ranges 10 and 15), and the existence of an eddy on the left bank (between data ranges 15 and 25). MoBed2 produced a flow field where these phenomena are clearly identifiable, while results attained by Telemac-2D only suggest that some disturbances occur at the aforementioned locations. Unfortunately, SWE-SPHysics failed to mirror the complex velocity distribution in the river bend.

\subsection{Unsteady flow analysis}

The requirements of the SPW-SPHysics model with regard to the small time step needed as a result of a large number of particles, consequently lead to extremely long computation time. This setback made it self-evident that it would be unjustifiable to engage this model for elongated simulations of the 2-D unsteady flow in natural watercourses. This model was therefore omitted from the second case study. The two remaining models, Telemac-2D and MoBed2, were applied using the field measurements described in Section 3.2. The measured discharges were set as the upstream boundary condition, while known water level elevation was provided at the downstream boundary. The simulation time was selected to correspond to the data collection time, with three additional days as the stabilization period, thus resulting in an eight-day simulation. The flow computations were set to incorporate

Table 2. Unsteady flow analysis - Error norms for the u velocity component

\begin{tabular}{|c|c|c|c|c|c|c|}
\hline \multirow{2}{*}{ Data range } & \multicolumn{3}{|c|}{ MoBed2 } & \multicolumn{3}{c|}{ Telemac-2D } \\
\cline { 2 - 7 } & $\mathbf{L}_{1}$ & $\mathbf{L}_{2}$ & $\mathbf{L}_{\omega}$ & $\mathbf{L}_{1}$ & $\mathbf{L}_{2}$ & $\mathbf{L}_{\omega}$ \\
\hline 1 & 0.453 & 0.202 & 0.138 & 0.102 & 0.051 & 0.035 \\
\hline 2 & 0.523 & 0.260 & 0.215 & 0.938 & 0.369 & 0.198 \\
\hline 3 & 0.258 & 0.136 & 0.107 & 0.211 & 0.120 & 0.099 \\
\hline 4 & 0.231 & 0.093 & 0.058 & 0.543 & 0.247 & 0.172 \\
\hline 5 & 0.379 & 0.160 & 0.099 & 0.32 & 0.146 & 0.112 \\
\hline 6 & 0.275 & 0.138 & 0.113 & 0.189 & 0.095 & 0.065 \\
\hline 7 & 0.403 & 0.181 & 0.104 & 0.275 & 0.135 & 0.104 \\
\hline
\end{tabular}


Table 3. Unsteady flow analysis - Error norms for the $v$ velocity component

\begin{tabular}{|c|c|c|c|c|c|c|}
\hline \multirow{2}{*}{ Data range } & \multicolumn{3}{|c|}{ MoBed2 } & \multicolumn{3}{|c|}{ Telemac-2D } \\
\hline & $\mathrm{L}_{1}$ & $L_{2}$ & $\mathbf{L}_{\infty}$ & $\mathrm{L}_{1}$ & $\mathrm{~L}_{2}$ & $\mathbf{L}_{\infty}$ \\
\hline 1 & 0.715 & 0.300 & 0.188 & 0.204 & 0.116 & 0.103 \\
\hline 2 & 0.513 & 0.261 & 0.214 & 0.506 & 0.233 & 0.151 \\
\hline 3 & 0.172 & 0.072 & 0.037 & 0.217 & 0.105 & 0.082 \\
\hline 4 & 0.197 & 0.115 & 0.105 & 0.475 & 0.194 & 0.113 \\
\hline 5 & 0.396 & 0.205 & 0.144 & 0.321 & 0.178 & 0.161 \\
\hline 6 & 0.576 & 0.239 & 0.134 & 0.279 & 0.124 & 0.091 \\
\hline 7 & 0.925 & 0.548 & 0.515 & 0.687 & 0.451 & 0.431 \\
\hline
\end{tabular}
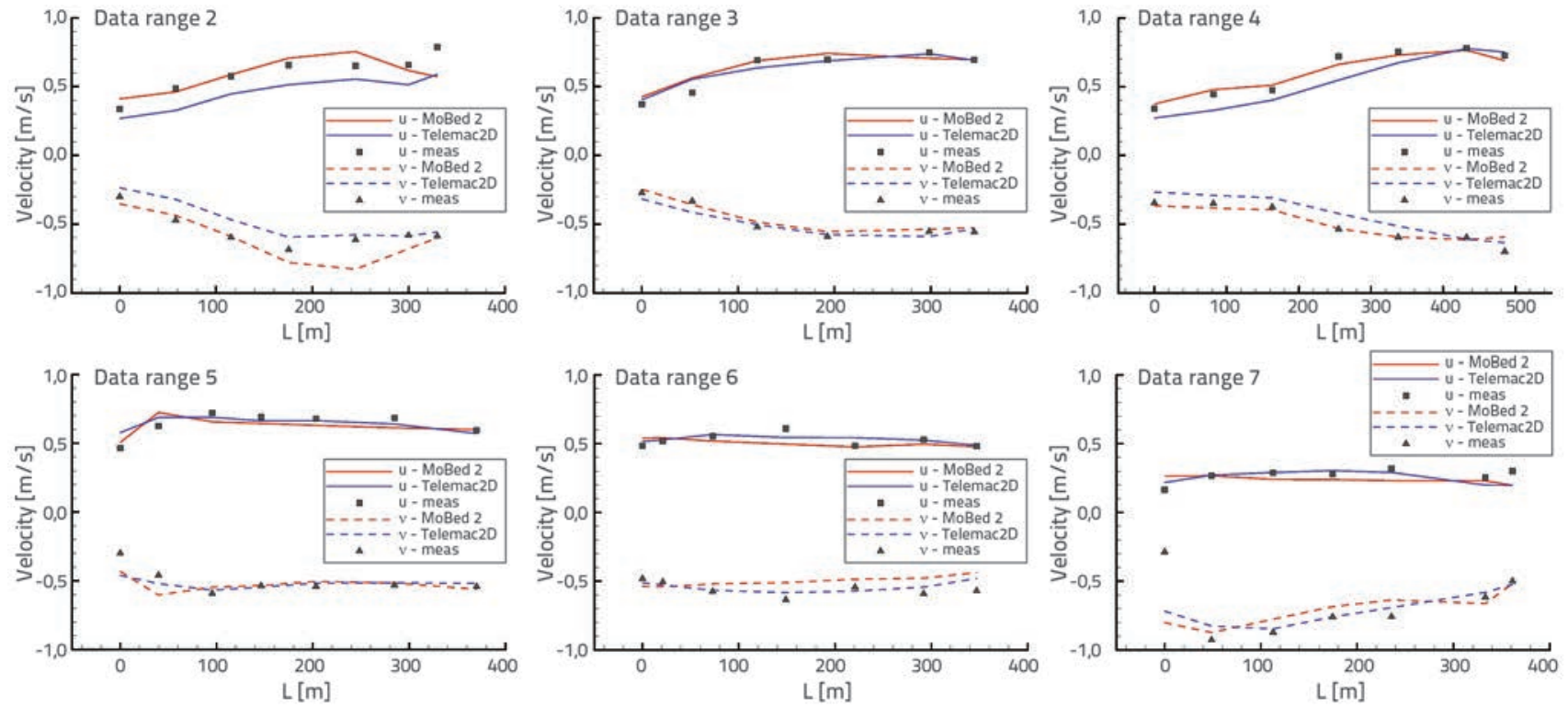

Figure 7. Unsteady flow analysis - velocity components $u$ and $v$

the horizontal free-surface elevation and zero-velocity field as initial conditions. The models were calibrated by altering the value of the Manning's roughness coefficient, until reasonable correspondence was achieved between the measured and computed free-surface elevations [28]. The Manning coefficient value of $n=0.03 \mathrm{~m}^{-1 / 3} \mathrm{~s}$ was obtained. The assessment of the results was done by comparing the measured and computed $\mathrm{u}$ and $v$ velocity components. Figure 7 presents the results at the data range from 2 to 7 , where measured and computed values of both velocity components are presented. Comparing the computational results to measured values in the data range from 2 and 4, it seems that MoBed2 produces slightly better results. Nevertheless, in the remaining data ranges, both models produced results that sufficiently correspond to measurement results. Therefore, in order to better evaluate the results, the accuracy of these models was additionally examined by computing $L_{1}, L_{2}$ and $L_{\infty}$ error norms for seven data ranges. Results obtained for both velocity components are given in Table 2 and Table 3. The analysis of computed error norms confirms that both models (Telemac-2D and MoBed2) produce errors of the same order of magnitude when applied to a field case study. This conclusion is valid for both velocity components. Although the same level of accuracy was achieved for both models, the execution times differed significantly: 0.5 hours for MoBed 2 and 2 hours for Telemac-2D. MoBed 2 had an edge over Telemac-2D, as structured body-fitted solvers are more efficient for flow simulations in simple domains.

\section{Conclusion}

The presented study focuses on the performance of different numerical approaches in natural watercourses modelling. Three different techniques were considered, the finite element method utilizing an unstructured mesh, the finite difference method employing a structured mesh, and a mesh-free method relying on smoothed particle hydrodynamics. Special attention was paid to the performance of the SWE-SPH models applicability to natural watercourses modelling, as being representative of the mesh-free methods. In order to determine whether one among the examined approaches shows predominant behaviour, the 
models were applied for the simulation of two test cases. The first test case was a steady flow simulation. The investigated models were evaluated using laboratory measurements of a steady flow in a river bend as the benchmark. Although the results obtained by the SWE-SPH model regarding the river bend itself proved inferior to the two other models, the results this method produced downstream of the curve showed the best agreement with the measurements. This indicates that an improvement of the SWE-SPH model could result in satisfying simulation results for steady flow analysis in natural watercourses. Regrettably, this model's greatest advantage, the absence of computational mesh, has also proven to be its prominent weakness. Considering that SWE-SPH uses particles to describe flow, situations such as the steady flow laboratory example with complex flow domain, require an extensive number of particles. Correspondingly, the time step needs to be significantly reduced, thus making it impractical for long term simulations. Nevertheless, smoothed particle methods engage a large number of research efforts, making future resolution of these deficiencies plausible.

As a consequence of previously noted weaknesses, only Telemac-2D and MoBed2 were utilized for the second test case, i.e. the unsteady flow analysis. The flow fields acquired by both of these models displayed favourable compliance with the measurement data, neither of them proving to be significantly more accurate than the other. Ultimately, it can be concluded that at present stage of development the grid based methods remain superior over the mesh-free methods, when applied to long term simulations of flow for natural watercourses.

\section{Acknowledgements}

This work was funded by the Ministry of Education and Science of the Republic of Serbia, Project Number TR 37009 and Project Number TR 37010.

\section{REFERENCES}

[1] Horvat, Z., Isic, M., Spasojevic, M.: Two dimensional river flow and sediment transport model, Environmental Fluid Mechanics, 2014, https://doi.org/10.1007/s10652-014-9375-y

[2] Galland, J.C., Goutal, N., Hervouet, J.M.: TELEMAC: A new numerical model for solving shallow water equations. Advances in Water Resources, 14 (1991) 3, pp. 138-148.

[3] Budinski, L., Spasojevic, M.: 2-D Modelling of Flow and Sediment Interaction - Sediment Mixtures, Journal of Waterway, Port, Coastal, and Ocean Engineering, 140 (2013) 2, pp. 199-209.

[4] Monaghan, J.J.: Simulating Free Surface Flows with SPH, Journal of Computational Physics, 110 (1994), pp. 399-406, https://doi. org/10.1006/jcph.1994.1034

[5] Džebo, E., Žagar, D., Krzyk, M., Četina, M., Petkovšek, G.: Different ways of defining wall shear in smoothed particle hydrodynamics simulations of a dam-break wave, Journal of Hydraulic Research, 52 (2014) 4, pp. 453-464.

[6] Budinski, Lj.: MRT lattice Boltzmann method for 2D flows in curvilinear coordinates, Computers \& Fluids, 96 (2014), pp. 288301, https://doi.org/10.1016/j.compfluid.2014.03.007

[7] Ying, X., Jorgeson, J., Wang, S.S.Y.: Modeling dam-break flows using finite volulme method on unstructured grid, Engineering Applications of Computational Fluid Mechanics, 3 (2009) 2, pp. 184194.

[8] Smith, C., Bates, P.D., Anderson, M.G.: Development of an inundation mapping capa- bility using high resolution finite element modelling, Final Technical Report, European Research Office of the U. S. Army, London, England, 1997.

[9] Erduran, K.S.: Fourth order finite volulme solution to shallow water equations and application, International Journal for Numerical Methods in FLuids, 73 (2013), pp. 637-659.
[10] Cioffi, F., Gallerano, F.: A two-dimensional self-adaptive hydrodinamics scheme for the assessment of the effects of structures on flooding phenomena in river basins, River Research and Application, 19 (2003), pp. 1-26, https://doi.org/10.1002/ rra.691

[11] Vacondio, R., Rogers, B.D., Stansby, P.K.: Accurate particle splitting for smoothed particle hydrodynamics in shallow water shock capturing, International Journal for Numerical Methods in Fluids, 69 (2012), pp. 1377-1410, https://doi.org/10.1002/fld.2646

[12] Vacondio, R., Rogers, B.D, Stansby, P.K., Mingosa, P.: SPH Modeling of Shallow Flow with Open Boundaries for Practical Flood Simulation, Journal of Hyidraulic Engineering, 138 (2012) 6, pp. 530-541.

[13] Vacondio, R., Rogers, B.D., Stansby, P.K.: Smoothed Particle Hydrodynamics: Approximate zero-consistent 2-D boundary conditions and still shallow-water tests, International Journal for Numerical Methods in Fluids, 69 (2012), pp. 226-253, https://doi. org/10.1002/fld.2559

[14] Hervouet, J.M.: Hydrodynamics of Free Surface Flows: Modelling with the Finite Element Method, John Wiley \& Sons Ltd, West Sussex, UK, 2007, https://doi.org/10.1002/9780470319628

[15] Yanenko, N.N.: The Method of Fractional Steps, Translated by Holt M. Springer-Verlag, New York, 1971, https://doi.org/10.1007/9783-642-65108-3

[16] Holly, F.M. Jr., Preissmann, A.: Accurate Calculation of Transport in Two Dimen- sions, Journal of the Hydraulics Division, Proceedings of the American Society of Civil Engineers, 103 (1977) HY11, pp. 12591277.

[17] Isic, M., Horvat, Z., Spasojevic, M.: Advection step in the splitoperator approach applied to river modeling, Applied Numerical Mathematics, 72 (2013), pp. 1-18, https://doi.org/10.1016/j. apnum.2013.05.001 
[18] Biringen, S., Chow, C.Y.: An Introduction to Computational Fluid Mechanics by Example, John Wiley \& Sons Inc., Hoboken, NJ., 2011, https://doi.org/10.1002/9780470549162

[19] Crank, J., Nicolson, P.: A practical method for numerical evaluation of solutions of partial differential equations of the heatconduction type, Advances in Computational Mathematics, 6 (1996), pp. 207-226, https://doi.org/10.1007/BF02127704

[20] Hsieh, T.Y., Yang, J.C.: Implicit Two-Step Split-Operator Approach for Modelling Two-Dimensional Open Channel Flow, Journal of Hydroscience and Hydraulic Engi-neering, 22 (2004) 2, pp. 113-139.

[21] Lucy, L.B.: A numerical testing of the fission hypothesis, Astronomical Journal, 82 (1977), pp. 1013-1024, https://doi. org/10.1086/112164

[22] Gingold, R.A., Monaghan, J.J.: Smoothed particle hydrodynamics: theory and appli- cation to non-spherical stars, Monthly Notices of the Royal Astronomical Society, 181 (1977), pp. 375-389, https:// doi.org/10.1093/mnras/181.3.375

[23] Shaofan, L., Wing, K.L.: Meshfree Particle Methods, SpringerVerlag, Berlin, Heidelberg, 2004.
[24] Elder, J.W.: The Dispersion of Marked Fluid in Turbulent Shear Flow, Journal of Fluid Mechanics, 5 (1959) 4, https://doi.org/10.1017/ S0022112059000374

[25] Kapor, R.: Mathematical model of flow in shallow flow domains with space averaged basic equations. Ph.D. dissertation, University of Belgrade, 1998.

[26] Muste, M., Yu, K., Pratt, T.: Abraham, D., Practical aspects of ADCP data use for quantification of mean river flow characteristics, Part II: fixed-vessel measurements, Flow Measurement and Instrumentation, 15 (2004), pp. 17-28, https://doi.org/10.1016/j. flowmeasinst.2003.09.002

[27] Muste, M., Yu, K., Spasojevic, M.: Practical aspects of ADCP data use for quan- tification of mean river flow characteristics; Part I: moving-vessel measurements, Flow Measurement and Instrumentation, 15 (2004), pp. 1-16, https://doi.org/10.1016/j. flowmeasinst.2003.09.001

[28] Budinski, Lj., Spasojević, M., Isić, M., Horvat, Z.: 2- and 3-D unsteady flow and transport along the Danube River between data ranges 1 (rkm 1438) and 7 (rkm 1432) - models' calibration, Closing Conference - Danube EHT 2010 - Hungary-Serbia IPA Crossborder Co-operation Programme, Subotica, 2011. 